\title{
Determination of heavy metals and phytochemical analysis of some selected medicinal plants
}

\author{
${ }^{1 *}$ S.K. Gunavathy, ${ }^{2}$ H. Benita Sherine \\ ${ }^{1}$ Department of Chemistry, Srimad Andavan Arts and Science College (Autonomous), Tiruchirappalli -620 005 \\ ${ }^{2}$ Department Chemistry, Periyar E.V.R. College (Autonomous), Tiruchirappalli -620 023 \\ Corresponding Author: skguna2019@gmail.com
}

Available online at: www.isroset.org

Received: 20/May/2019, Accepted: 14/Jun/2019, Online: 30/Jun/2019

\begin{abstract}
Natural products had been essentially used by many cultures and traditions from thousands of years. Plants synthesize massive varieties of substances called secondary metabolities (Phytocompounds) and accumulated in it. The possible bioactive phytocompounds like alkaloids, flavanoids, and phenolic compounds, steroids and coumarins etc., are possible sources for drug discovery. A study was conducted to analyse the presence of traces of essential and non essential heavy metals in the preferred medicinal plants. AAS is used to examine the presence of heavy metals in the selected medicinal plant. Results obtained in the present study showed that the medicinal herb analysed contain heavy metals ( $\mathrm{Fe}, \mathrm{Cu}, \mathrm{Mn}, \mathrm{Zn}$, $\mathrm{Ni}, \mathrm{Co}, \mathrm{Pb}, \mathrm{Al}, \mathrm{V}, \mathrm{Cr}, \mathrm{Mo}, \mathrm{Hg}$, As and $\mathrm{Cd}$ ). The concentration ( $\mathrm{ppm}$ ) of heavy metals in the plant extracts like Plectranthus mollis, Elaeagnus conferta and Grewia tilaefolia leaf extracts were found using atomic absorption spectrophotometer. The qualitative analysis showed that alkaloids were mainly seen in most of the samples of Hydro alcoholic leaf extracts. Total phenol, Flavonoid, Steroids, Alkaloid and Tannins were present in all the three samples extracted by Hydro alcoholic leaf extracts. Total phenol and Alkaloid were seen more in leaf samples, from the judgment of the results with the defined permissible limits, it was accomplished that the levels of heavy metals present in the herb falls in the permissible limits for consumed medicinal herbs. Purpose of this study is to determine heavy metals contents in chosen herbal plants and also to highlight the health concerns related to the presence of toxic levels of heavy metals. The presence of high amount of phytochemical compounds put forward that the Grewia tilaefolia plant has higher medicinal value and can be extensively studied to extract the natural compounds which are beneficial to human beings and that could be commercialized for higher production than using synthetic drugs with side effects.
\end{abstract}

Keywords: phytochemical, Heavy Metal, Atomic Absorption Spectroscopic, etc.,

\section{INTRODUCTION}

In India, the use of plants for medicinal behavior dates back to Vedic era. About 500 plants with medicinal uses are mentioned in ancient texts and around 800 plants have been used in indigenous system of medicine [1]. Vast ethnobotanical and ethnopharmacological knowledge exists in India from ancient times. According to world health association report about $80 \%$ of the world population depend on plant based medicines and traditionally used herbs as their primary health care (WHO). The herbal drugs are well recognized for their therapeutical benefits. Nutritionally important mineral elements build up in the plants which are used as herbs and food supplements. Elements like Lead, cobalt, Chromium, Cadmium etc., which do not use the plants directly but accumulate in the plants and are harmful to human health when consumed [2].

The majority common heavy metals which implicated toxicity in humans include lead, mercury, arsenic, and cadmium, although aluminum and cobalt may also cause toxicity. Therefore, the world health organization recommends that medicinal plants, which form the raw materials for most herbal remedies, should be checked for the attendance of heavy metals. Plants are the sources of natural products which act as models for new pharmacologically active compounds. Ceropegia juncea (Roxb.) is a plant which belongs to the family Asclepiadoideae having wide medicinal properties and is being used in different conventional medical systems and by tribal people for curing different ailments. The present test plant has vast ethnobotanical and ethnomedicinal properties [3]. 
The plant Ceropegia juncea (Roxb.) was identified as one of the Soma plant. There has been significantly increase in the usage of herbal products and drugs in recent years. Because of this, it is essential that the quality of plant-based drugs must be assured safe prior to their use. Several works have been reported on the phytochemical and biological behavior of medicinal plants, although there is few reports in regard to the heavy metal concentrations in the medicinal plants and herbal drugs used [4]. The medicinal herbs can cause health risks due to the presence of poisonous metals such as Nickel, Lead, Cadmium, Manganese and Mercury, which are hazardous to humans. Pharmacological assessment of the medicinal plants was recommended for purity and quality of the drugs coming from the botanicals [5].

Bryonia alba $\mathrm{L}$., is one of the smallest genus in the family cucurbitaceae, consists of 12 species distributed throughout the Europe and West Asia [6,7]. It has been conventionally used in the treatment of dissimilar diseases such as cough, frontal pain, inflammation of serous tissues, peritonitis, pneumonia, jaundice, typhoid, rheumatism, brain disorders with serous exudation and as a heart tonic [7]. Nowadays, the interest in chemical analysis of medicinal herbal products is growing owing to the continuing developments in nutrition and in biochemical surveying and mineral prospecting [8,9]. Additionally, the studies related to therapeutic plants not only aim to characterize the active mechanism found in plants, but also for scientific support of its therapeutic properties [10].

Macro, micro and trace elements are known to play a vital role in biological functions in plants and in human metabolic reactions. Moreover, trace elements play an important role in the arrangement of bioactive chemical constituents in medicinal herb plants and thus are responsible for their medicinal and toxic properties accordingly [11-12]. Several number of techniques such as voltammetery, atomic absorption spectrometry (AAS) [13], inductively coupled plasma atomic optical emission spectrometry (ICP-OES) [14], X- ray fluorescence (XRF) [15], differential beat cathode stripping voltamperometry (DPCSV) [16] and instrumental neutron activation analysis (INAA) [17] are normally used for the determination of trace elements in medicinal herbal plants. Because of its specificity, sensitivity, high precision, simplicity, rapid analysis, low cost, low detection limit, and wide linear range, AAS is the most widely recommended device used in analytical procedures for the trace metal analysis found in complex biological samples.

AAS methods are considered as direct aspiration determinations where they are talented as single element analysis and are relatively free of inter element spectral interferences. In other words, the use of special light sources shaped by the cathode lamp is emitted from excited atoms of the same element of interest and specific spectrum selection allows the quantitative determination of individual components of a multi element mixture [18]. AAS method is preferred for present study as it a reliable techniques, which is more accurate as an accurate and easy to use [19].

Medical plants are plants containing built in active ingredients used to to cure disease and relieve from pain [20]. The use of traditional medicines and medicinal plants in mainly developing countries as remedial agents for the preservation of health has been broadly observed [21]. In Modern-days pharmacopoeia however contains atleast 25\% drugs derived from plants and many others, which are synthetic analogues, built on prototype chemical substances isolated from plants. Involvement in medicinal plants as a re-budding health support has been fuelled with the rising charges of prescription drugs in safeguarding of personalized health as well as well being and the bio prospecting of new plant derived drugs [22]. The ongoing development recognition concerning medicinal plants is due to include increasing faith in herbal medicine [23]. On the top of that, an increasing confidence on the use of these medicinal plants in the industrialized organizations has been traced towards the extraction and development of drugs and chemotherapeutics from these plants as well as from predictably used herbal remedies [24]. The therapeutic properties of plants could be based on their anti-oxidant, anti-microbial, antipyretic effects of the phytochemicals constituents in them [25]. According to World Health Organization, medicinal plants would be the maximum source to obtain an array of drugs. Thus, such plants should be investigated to better understanding for their properties, safety practices in addition to usefulness [26].

In India, the ayurvedic system has a good rapport on plants or plant products and the determination of their morphological, pharmacological or pharmacognostical characters can provide a better understanding of their active principle and mode of action. However a large number of tropical plants have not lately been studied in detail for their chemical constituents. So, in this regard we focused on phytochemical aspects in 10 selected indigenous plants of India: 1) Garcinia indica [GI] (leaves); 2) Jatropha curcas [JC] (leaves);3) Nigella sativa [NS] (leaves); 4) Levisticum officinale [LO] (leaves); 5) Dracaena loureiri [DL] (leaves) 6); Woodfordia fruticosa [WF] (stem);7) Vaccinium macrocarpon[VM](leaves) 8) Foeniculum vulgare [FV] (stem); 9) Sapindus saponaria $[\mathrm{SS}]$ (pericarp) ; 10)Annona squamosa [AS] (seeds).

Heavy metals are ubiquitous in trace concentrations in soils and the plants grown in these soils face the heavy metal stress, and causes changes in production of secondary metabolites. High levels of heavy metal contagion in medicinal or other plants may 
suppress secondary metabolite production. It is essential to maintain safety, quality and efficacy of the plants and their products to keep away from serious health problems. Hence in the present study an attempt has been also made to analyze heavy metals (Iron, Copper, Manganese, Zinc, Nickel, Cobalt, Lead, Aluminum, Vanadium, Chromium, Molybdenum, Mercury, Arsenic, and Cadmium) by AAS technique. In the present work, fourteen minor and trace nutrient elements (Fe, $\mathrm{Cu}, \mathrm{Mn}, \mathrm{Zn}, \mathrm{Ni}, \mathrm{Co}, \mathrm{Pb}$, $\mathrm{Al}, \mathrm{V}, \mathrm{Cr}, \mathrm{Mo}, \mathrm{Hg}$, As and Cd) were determined in Plectranthus mollis, Elaeagnus conferta and Grewia tilaefolia leaf extracts.

\section{MATERIALS AND METHODS}

\subsection{Analysis of metals by atomic absorption spectrophotometer}

\subsubsection{Sample collection}

The samples are cleaned and dried under shade. Then, the samples are dried in an oven at $40^{\circ}-50^{\circ} \mathrm{C}$ till a constant weight is obtained. The dried samples are then, ground and powdered with pestle and mortar. Samples are labelled and stored in precleaned polyethylene bottles for further analysis.

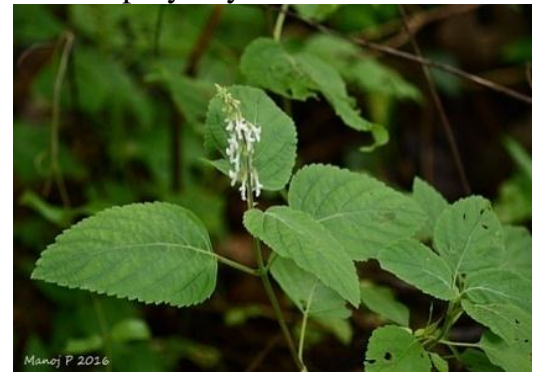

Plectranthus mollis

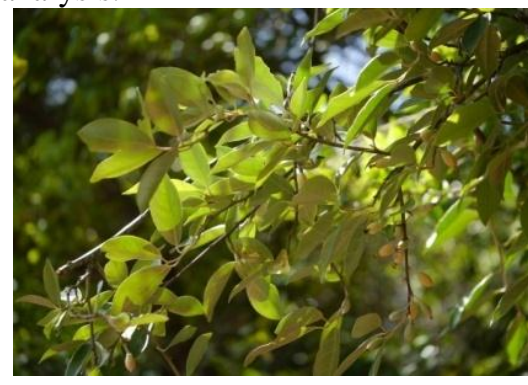

Elaeagnus conferta

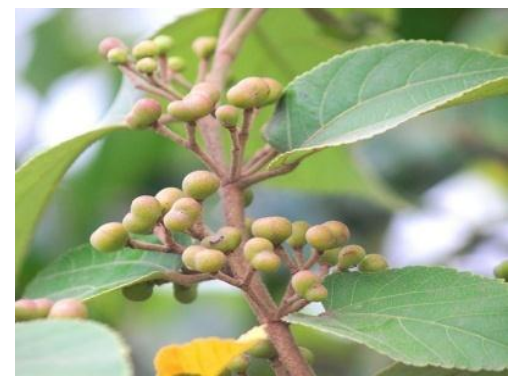

Grewia tilaefolia

Image:1 Experimental plants images

\subsubsection{Reagents and apparatus}

All the reagents such as $\mathrm{HNO}_{3}$ and $\mathrm{H}_{2} \mathrm{O}_{2}$ used in the study are purchased from MERCK (Analytical Grade). De-ionized water is used for all analytical work and all the glasswares, polyethylene bottles, pipette tips were washed with $1 \% \mathrm{HCl}$, rinsed with de-ionized water before preparing standard reagents and samples.

\subsubsection{Sample preparation-ash method}

The fine powder is used for drying to ashing. Necessary precautions are taken at every step to avoid metallic contamination in any form. Pre-cleaned silica crucibles are kept in muffle furnace maintained at $600^{\circ} \mathrm{C}$. Until the weight of the crucible reaches a constant level, the crucible is kept in the furnace. Powdered plant material $(5 \mathrm{gm})$ are taken in the silica crucible and maintained in a muffle furnace at $600^{\circ} \mathrm{C}$ for $6 \mathrm{hrs}$. The crucible is now taken out and cooled at room temperature by keeping it in desiccators and then, the ash values are measured. Then, the ash is dissolved in 100ml of $5 \%$ HCL. The dissolved ash solutions are filtered through Whatman filter paper No.40 and are stored in tightly capped plastic bottles. The prepared solutions are directly used for the determination of various elements by using flame photometry and AAS.

\subsubsection{Digestion of samples (sample preparation-acid digestion)}

A Multiwave 3000 micro oven system (from Anton paar, USA) with 16 positions for Teflon vessels is being used here. The digestion vessels are provided with a controlled pressure, temperature and release valve. Before use, all Teflon vessels are soaked with $10 \% \mathrm{HNO}_{3}$. The system is initially programmed by giving gradual rise of $20 \%, 40 \%$, and $50 \%$ power for 5,15 and 20 minutes, respectively for the due warming up. The powder samples are being used without any further treatment for sample preparation. $0.2 \mathrm{gm}$ of sample is weighed into the Teflon vessels followed by digestion mixture of $\mathrm{HNO}_{3}$ and $\mathrm{H}_{2} \mathrm{O}_{2}$ in the ratio of $3: 1$. According to the nature of samples, the ratio is being applied.

The resulting solution after microwave digestion is filtered through Whatman 40 filter paper (if necessary) and diluted to $50 \mathrm{ml}$ with de-ionized water. A sample blank containing only acid mixture is prepared at the same time. The method of standard addition is generally adapted to calibrate the instrument before going for the observation of the samples.

\subsubsection{Determination of metals}

All the atomic measurements are carried out with PerkinElmer model 400/HGA 900/AS 800 coupled with Mercury Hydride System-15 (MHS-15) and Flame Photometer. The Hallow cathode lamps (HCL) for Fe, Cu, Mn, Zn, Mg, Mo etc., and Electrode less Discharge Lamp (EDL) for $\mathrm{Cd}, \mathrm{Pb}, \mathrm{Hg}$ and $\mathrm{As}$ analyses are used as a light source to provide specific 
wavelength of the elements to be determined. High purity (99.999\%) Acetylene and Nitrous oxide are used to provide constant thermal energy for atomization process and Argon gas used for carrier gas removal purposes for Graphite furnace.

\subsubsection{Atomic: Absorption Spectrophotometer (AAS)}

After calibrating the instrument with prepared working standard, the $10 \mathrm{ml}$ of digested liquid sample is pipetted out to a specific container of Mercury Hydride system analyser followed by adding $1.5 \% \mathrm{HCl}$ of $10 \mathrm{ml}$ as diluents for each flask and blank, $3 \%$ of $\mathrm{NaBH}_{4}$ solution in $1 \%$ of $\mathrm{NaOH}$ is run through the reaction flask to quartz cell without heating against the calibration curve obtained from concentration vs absorbance of the prepared known concentration on the day of the analysis.

\subsection{Quantitative estimations of Phytochemicals}

2.2.1 Estimation of total phenol content(Spanos and Wrolstad, 1990)

In a test tube, $200 \mu \mathrm{l}$ of the extract $(1 \mathrm{mg} / \mathrm{ml})$ was mixed with $1 \mathrm{ml}$ of Folin-Ciocalteu reagent and $800 \mu 1$ of sodium carbonate. After shaking, it was kept for $2 \mathrm{hrs}$ for reaction. The absorbance was measured at 750nm. Using gallic acid monohydrate, standard curve was prepared and linearity was obtained in the range of $10-50 \mu \mathrm{g} / \mathrm{ml}$.

Using the standard curve, the total phenol content of the extract was determined and expressed as gallic acid equivalent in $\mathrm{mg} / \mathrm{gm}$ of the extract.

2.2.2 Estimation of flavonoid (Swain and Hillis Method, 1959)

$0.2 \mathrm{ml}$ of the extract was taken in a test tube and the final volume was made up to $2 \mathrm{ml}$ with distilled water and to this $4 \mathrm{ml}$ of vanillin reagent was added rapidly. Exactly after 15minutes, the absorbance was recorded at 500nm against blank. The unknown was read from a standard curve prepared using different concentrations of phosphoglycinol.

\subsubsection{Estimation of Alkaloids (Harborne, 1973)}

$5 \mathrm{gm}$ of sample was weighed into a $250 \mathrm{ml}$ beaker and $200 \mathrm{ml}$ of $10 \%$ acetic acid in ethanol was added, covered and allowed to stand for $4 \mathrm{hrs}$. This was filtered and the extract was concentrated on a water bath to one quarter of the original volume. Conc. ammonium hydroxide was added drop wise to the extract until the completion of precipitation. The whole solution was allowed to settle and the precipitate was collected and washed with dilute ammonium hydroxide and then filtered. The residue is alkaloid, which was dried and weighed.

\subsubsection{Estimation of total tannins (Okwu, 2005)}

$5 \mathrm{gm}$ of the sample was boiled with $400 \mathrm{ml}$ of water for 30 minutes, cooled and filtered through a Whatman no. 1 filter paper and it was made up to $500 \mathrm{ml}$ with distilled water. About $0.5 \mathrm{ml}$ of the sample was made upto $10 \mathrm{ml}$ with distilled water. To this, $0.5 \mathrm{ml}$ of colouring agent was added. The blue colour was read at $760 \mathrm{~nm}$ against reagent blank after 30 minutes at room temperature. A standard was also run simultaneously at concentrations range of $20-100 \mu \mathrm{g}$ and the amount of tannic acid equivalent was calculated. The values are expressed as $\mathrm{mg}$ of tannic acid equivalent/ gm of dried sample.

\subsubsection{Estimation of Steroids}

$1 \mathrm{ml}$ of test extract of steroid solution was transferred into $10 \mathrm{ml}$ volumetric flasks. Sulphuric acid (4N, 2ml) and iron (III) chloride $(0.5 \% \mathrm{w} / \mathrm{v}, 2 \mathrm{ml})$ were added, followed by potassium hexacyanoferrate (III) solution $(0.5 \% \mathrm{w} / \mathrm{v}, 0.5 \mathrm{ml}) . \mathrm{The} \mathrm{mixture}$ was heated in a water-bath maintained at $70 \pm 20 \mathrm{C}$ for 30 minutes with occasional shaking and diluted to the mark with distilled water. The absorbance was measured at $780 \mathrm{~nm}$ against the reagent blank.

\section{RESULT AND DISCUSSION}

\subsection{Analysis of metals by atomic absorption spectrophotometer}

The concentrations of trace elements $\mathrm{Fe}, \mathrm{Al}, \mathrm{Zn}$, and $\mathrm{Na}$ were found in the medium range of 5.2 to $13 \mathrm{mg} / 100 \mathrm{~g}$ dry weight of the sample. $\mathrm{Ni}, \mathrm{Cd}$ and $\mathrm{Pb}$ are toxic elements which occur naturally in plants as a result of uptake, generally in places with high concentration caused by atmospheric and industrial fallout [27]. Determinations of quantities of metals by atomic absorption spectrophotometer are mentioned in table 1.

Table: 1 Heavy metal analysis of hydro alcoholic leaf extracts

\begin{tabular}{|l|c|c|c|}
\hline \multicolumn{1}{|c|}{ Elements analyzed } & Plectranthus mollis & Eleagnus conferta & Grewia tilaefolia \\
\hline Iron $(\mathrm{Fe})$ & 0.512 & 0.421 & 0.815 \\
\hline Copper $(\mathrm{Cu})$ & 0.023 & 0.048 & 0.138 \\
\hline
\end{tabular}




\begin{tabular}{|c|c|c|c|}
\hline Manganese (Mn) & 0.078 & 0.087 & 0.14 \\
\hline Zinc (Zn) & 0.127 & 0.092 & 0.163 \\
\hline Cobalt (Co) & 0.752 & 0.436 & 0.842 \\
\hline Aluminum (Al) & 3.715 & 2.118 & 4.381 \\
\hline Vanadium (V) & 1.42 & 0.872 & 1.727 \\
\hline Chromium (Cr) & 0.189 & 0.015 & 0.255 \\
\hline Molybdenum (Mo) & 0.285 & 0.186 & 0.297 \\
\hline Cadmium (Cd) & 0.215 & 0.154 & 0.294 \\
\hline
\end{tabular}

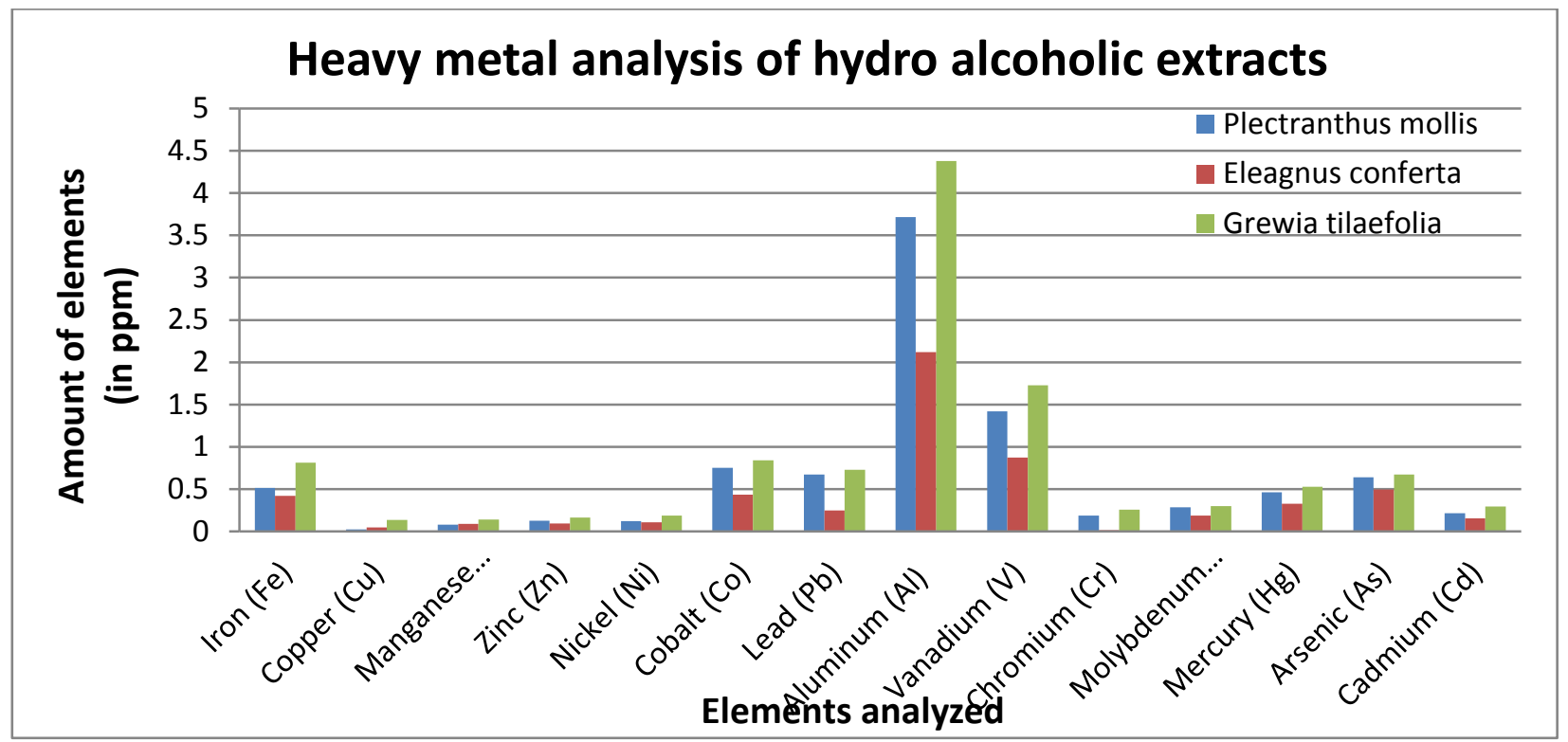

Image: 2 Graphical representation of Quantitative estimation of bioactive phytoconstituents in the Hydro alcoholic leaf extracts

\section{Iron (Fe)}

Iron (Fe) is considered an essential element necessary for human body. It is the main component of myoglobin, hemoglobin, and a number of enzymes that play an important role in the oxygenation of red blood cells. It is needed for a strong immune system as well as for energy production. It has been reported that iron severe deficiency results in anemia, which ranges from a fall in plasma ferreting to the strict iron deficiency that characterized by small red blood cells and low hemoglobin concentration level [27,28]. The daily necessity of Fe for a child is $10 \mathrm{mg} / \mathrm{day}$, whereas for an adult is $20 \mathrm{mg} / \mathrm{day}$. The Fe concentration in Plectranthus mollis, Elaeagnus conferta and Grewia tilaefolia leaf extracts of sample analyzed was found likewise $0.512 \mathrm{ppm}, 0.421 \mathrm{ppm}$ and $0.815 \mathrm{ppm}$. The maximum amount of Iron is present in Elaeagnus conferta leaf extracts. 


\title{
Copper $(\mathbf{C u})$
}

Following zinc and iron, copper is well thought-out the third most abundant trace element in the body. It has also been reported that it is an important catalyst for iron absorption. Its deficiency may be a risk factor for cardiovascular disease. When obvious copper deficiency occurs, symptoms such as neuropenia, cardiac disorders, osteoporosis and anemia may occur [29]. Plectranthus mollis, Elaeagnus conferta and Grewia tilaefolia leaf extracts of sample was analyzed and found to have copper content as $0.023 \mathrm{ppm}, 0.048 \mathrm{ppm}$ and $0.138 \mathrm{ppm}$ (dry weight of the sample). Among these Grewia tilaefolia has utmost amount of Copper, excess copper is toxic. Normal daily intake of copper is $2-5 \mathrm{mg}$ per day. In not poisonous plants if the permissible limit set by FAO/WHO [22] in 1984 was $3.00 \mathrm{ppm}$. From literature survey Bryonia alba L. roots copper is less than the permissible limit [30].

\section{Manganese (Mn)}

As known pyruvate carboxylase and superoxide dismutase are enzymes which holds manganese [28]. Plectranthus mollis, Elaeagnus conferta and Grewia tilaefolia leaf extracts of sample was analyzed and found to have $0.078 \mathrm{ppm}, 0.087 \mathrm{ppm}$ and $0.14 \mathrm{ppm}$, dry weight of the Manganese content in the sample. Among the three plants, Grewia tilaefolia has utmost amount of Manganese.

\section{Zinc (Zn)}

Zinc is considered as one of the main components of over 200 enzymes having both catalytic and structural roles including the alcohol dehydrogenase, ribonucleic polymerases, alkaline phosphatase, and carbonic anhydrase [31]. Scientific studies conducted on animals have shown that zinc deficiency occurred during pregnancy may cause developmental disorders in the offspring [32]. Low intake of zinc may cause coronary artery disease. The concentration of zinc in Plectranthus mollis, Elaeagnus conferta and Grewia tilaefolia leaf extracts of sample were analyzed and found to be $0.127 \mathrm{ppm}, 0.092 \mathrm{ppm}$ and $0.163 \mathrm{ppm}$ das dry weight of zinc in the sample. Grewia tilaefolia has maximum amount of Zinc is present.

\section{Lead (Pb), Cadmium (Cd), and Nickel (Ni)}

Plectranthus mollis, Elaeagnus conferta and Grewia tilaefolia leaf extracts of sample contains metals such as $\mathrm{Pb}(0.671,0.247$ and 0.73$) \mathrm{ppm} \mathrm{Cd}(0.215,0.154$ and 0.294$) \mathrm{ppm}$ and $\mathrm{Ni}(0.12,0.108$ and 0.185$) \mathrm{ppm}$ (dry weight of the sample). These elements are considered to be toxic in nature and thus their presence at trace level in various medicinal plant samples analyzed, may be due to the pollution happening from industrial activities and automobile [28]. Cadmium is measured a very hazardous to human health. Additionally, it causes high blood pressure, damages kidneys and liver [33].

\section{Cobalt (Co)}

Cobalt is one of the most important necessary components for the B12 vitamin and thyroid metabolism [27]. It is necessary in very small amounts in all mammals. It is used to treat different types of cancer in humans anemia treatment. The intake of high amount can cause heart diseases [18]. Cobalt is present in Plectranthus mollis, Elaeagnus conferta and Grewia tilaefolia leaf extracts of sample analyzed and the weight of the sample was found to be $0.752 \mathrm{ppm}, 0.436 \mathrm{ppm}$ and $0.842 \mathrm{ppm}$. Maximum amount of Cobalt is present in Grewia tilaefolialeaf extracs.

\begin{abstract}
Aluminum (Al)
Aluminum (Al) ions are considered toxic to most plants. It has negative results in being suppressed root growth and causing a series of irregular metabolic effects [36]. Being an important herbal plant in the world, Samples of Plectranthus mollis, Elaeagnus conferta and Grewia tilaefolia leaf extracts contain $3.715 \mathrm{ppm}, 2.118 \mathrm{ppm}$ and $4.381 \mathrm{ppm}$, dry weight of $\mathrm{t}$ Aluminum. Grewia tilaefolia has maximum amount of Aluminum is considered an important source of dietary Al.

\section{Molybdenum (Mo)}

Molybdenum (Mo) concentration found in Plectranthus mollis, Elaeagnus conferta and Grewia tilaefolia leaf extracts of sample and was found to have Molybdenum content as $0.285 \mathrm{ppm}, 0.186 \mathrm{ppm}$ and $0.297 \mathrm{ppm}$ dry weight of the ample. Grewia tilaefolia has maximum amount of Molybdenum. Trace amount of Mo is necessary for the body as it is mostly needed in the pancreas and plays a important role in the production of insulin. Deficiency of Mo results in the disorder of the liver, and the daily intake should not exceed $1.0 \mathrm{mg}$. Beyond this level is toxic [37]. When analyzed in the roots of four therapeutic plants namely; Ocimum basilicum, Poupulus nigra, Taraxacum officinale, and Convallaria maialis, its concentration varied from 0.82 to $9.2 \mathrm{ppm}$. Most of the samples usually having concentrations between 0.51 and $0.72 \mathrm{ppm}$ are considered the highest Mo concentration [33].
\end{abstract}

\section{Mercury (Hg)}


Mercury $(\mathrm{Hg})$ is enormously toxic trace metal pollutant. Bio-accumulation of $\mathrm{Hg}$ in plants and then its entry into the food chain results in long term health hazards [38]. The toxicity of $\mathrm{Hg}$ depends on its chemical state. Some forms of $\mathrm{Hg}$ are relatively nontoxic and have been used as medicines, e.g., for the behavior of syphilis. Speciation of mercury at trace and ultra-trace levels is a matter of current interest. The concentration of $\mathrm{Hg}$ in Plectranthus mollis, Elaeagnus conferta and Grewia tilaefolia leaf extracts of sample were analyzed to be $0.461 \mathrm{ppm}, 0.328 \mathrm{ppm}$ and $0.528 \mathrm{ppm}$ as dry weight of the samples. Grewia tilaefolia has maximum amount of Mercury.

\title{
Arsenic (As)
}

Arsenic (As) is a toxic contaminant in the environment, which results from anthropogenic and natural sources. It has been reported that plants growing in As contaminated soils accumulate As in their biomass [39]. Additionally, As may accumulate in soils and sediments owing to the use of arsenical pesticides, fertilizers, irrigation, and oxidation of unstable arsine in air disposal of industrial, municipal and animal waste [40,41]. Once a plant is contaminated with arsenic, it causes toxicity such as leaf chlorosis and necrosis, and also reduces growth. Different As species in plants show dissimilar toxicity, so it is important to quantify As in plants to better understand their metabolism. The concentration of arsenic in Plectranthus mollis, Elaeagnus conferta and Grewia tilaefolia leaf extracts of sample analyzed was found likewise $0.64 \mathrm{ppm}, 0.496 \mathrm{ppm}$ and $0.673 \mathrm{ppm}$ and it is the dry weight of the sample. Grewia tilaefolia has utmost amount of Arsenic.

\begin{abstract}
Vanadium (V)
The attention of Vanadium in Plectranthus mollis, Elaeagnus conferta and Grewia tilaefolia leaf extracts of sample analyzed was found to be $1.42 \mathrm{ppm}, 0.872 \mathrm{ppm}$ and $1.727 \mathrm{ppm}$ and it is the dry weight of the sample. Grewia tilaefolia has maximum amount of Vanadium. It is a potent inhibitor of many enzymes, lower plasma cholesterol levels, directly influence glucose metabolism in vitro, suggesting a role in its regulation and supposedly play a physiological role on levels of the endogenous antioxidant-glutathione representing its importance with respect to toxic interactions of chemicals [42]. Signs of excessive vanadium intake in humans includes gastrointestinal disturbances [43]. Vanadium was identified in approximately all the anti-cancer medicinal plants that are analyzed [44].
\end{abstract}

\section{Chromium (Cr)}

The concentration of Chromium in Plectranthus mollis, Elaeagnus conferta and Grewia tilaefolia leaf extracts of sample analyzed was found to be $0.189 \mathrm{ppm}, 0.015 \mathrm{ppm}$ and $0.255 \mathrm{ppm}$ and it is dry weight of the sample. Grewia tilaefolia has maximum amount of Chromium. $\mathrm{Cr}$ is an essential nutrient that potentiates insulin success and thus influences carbohydrate, lipid and protein metabolism [45]. However, the role of Chromium as cofactor for insulin action is not fully understood as studies from several in vivo and in vitro studies at the molecular level are ongoing [46]. So the high level from it can be due to usage of fungaceous pesticides and mostly useful copper oxides. Concentrations of outline elements in plants are often positively correlated with the abundance of these elements in growth media. In addition, soil is the main foundation of trace elements for plants both as micronutrients and as pollutants.

\subsection{Quantitative estimations of Phytochemicals}

Plants play important roles in discovery connected with new beneficial therapeutic agents and have received significant focus because of their bio- active substances like antioxidants, hypoglycemic and hypolipidemic factors. India has a prosperous record associated with applying different potent natural herbs and plant based components regarding management of different diseases. Plants have always been very good source of drugs and a number of currently available drugs happen to be derived directly or indirectly from them. Flavonoids tend to be most commonly known with regards to antioxidant nature. They are transformers which alter the body biochemical reactions to carcinogenic chemicals, viruses, and things that trigger allergies. Many plants show their characters for anticancer, anti-inflammatory, antibacterial and anti-allergic nature, and could be useful in therapeutic roles. Alkaloids tend to be organic and natural ingredients that have nitrogen, and are also physiologically vigorous together with sedative and analgesic roles. They are found in reducing stress and depression symptoms. Alkaloids tend to be poisonous when taken in mass amount due to their stimulatory effects, producing excitation associated with cell and nerve disorders. Phenolic compounds are some of the most extensive molecules among plant secondary metabolites, are known to act as normal antioxidants. Additionally, they serve as flower pigments which act as constitutive defense agents against invading organisms. Tannin and Steroids are extensively utilized in veterinary vaccines because their character as an adjuvant and helps in the improvement of resistant response. Many of them are useful in intracellular histo-chemistry staining permitting antibody access to intracellular protein molecules. The results extracted from our research are usually in agreement with the studies connected with other workers in the same field. Phytochemicals analysis of Plectranthus mollis, Elaeagnus conferta and Grewia tilaefolia leaf extracts of samples and their parameters values are presented in Table 2. 
Table: 2 Quantitative estimation of bioactive phytoconstituents in the Hydro alcoholic leaf extracts

\begin{tabular}{|c|c|c|c|c|c|c|c|c|c|c|c|c|c|}
\hline \multirow{3}{*}{$\begin{array}{r}\text { S. } \\
\text { No }\end{array}$} & \multirow{3}{*}{ Parameters } & \multicolumn{4}{|c|}{ Plectranthus mollis } & \multicolumn{4}{|c|}{ Eleagnus conferta } & \multicolumn{4}{|c|}{ Grewia tilaefolia } \\
\hline & & \multicolumn{3}{|c|}{ Triplicate value } & \multirow{2}{*}{$\begin{array}{c}\text { Expressed in } \\
\text { terms of } \\
\text { standards } \\
\text { mg/ml }\end{array}$} & \multicolumn{3}{|c|}{ Triplicate value } & \multirow{2}{*}{$\begin{array}{c}\text { Expressed in } \\
\text { terms of } \\
\text { standards } \\
\text { mg/ml }\end{array}$} & \multicolumn{3}{|c|}{ Triplicate value } & \multirow{2}{*}{$\begin{array}{c}\text { Expressed in } \\
\text { terms of } \\
\text { standards } \\
\mathrm{mg} / \mathrm{ml}\end{array}$} \\
\hline & & $\mathbf{A}$ & B & $\mathbf{C}$ & & A & B & $\mathbf{C}$ & & $\mathbf{A}$ & B & $\mathbf{C}$ & \\
\hline 1 & Total phenol & 14 & 14.5 & 14.3 & $14.27 \pm 0.25$ & 13.2 & 13.1 & 13.1 & $13.11 \pm 0.05$ & 18 & 15.3 & 17.3 & $16.85 \pm 1.42$ \\
\hline 2 & Flavonoid & 5.1 & 5.15 & 5.12 & $5.12 \pm 0.02$ & 3.07 & 3.86 & 3.22 & $3.38 \pm 0.42$ & 5.21 & 5.26 & 5.2 & $5.22 \pm 0.03$ \\
\hline 3 & Steroids & 3.21 & 3.27 & 3.08 & $3.18 \pm 0.09$ & 2.16 & 2.03 & 2.14 & $2.11 \pm 0.07$ & 4.26 & 4.58 & 4.2 & $4.34 \pm 0.20$ \\
\hline 4 & Alkaloid & 7.42 & 7.45 & 7.49 & $7.45 \pm 0.03$ & 6.42 & 6.41 & 6.3 & $6.37 \pm 0.06$ & 8.56 & 8.74 & 8.92 & $8.74 \pm 0.18$ \\
\hline 5 & Tannin & - & - & - & - & 5.41 & 5.39 & 5.38 & $5.39 \pm 0.01$ & 10.3 & 10.8 & 10.7 & $10.57 \pm 0.28$ \\
\hline
\end{tabular}

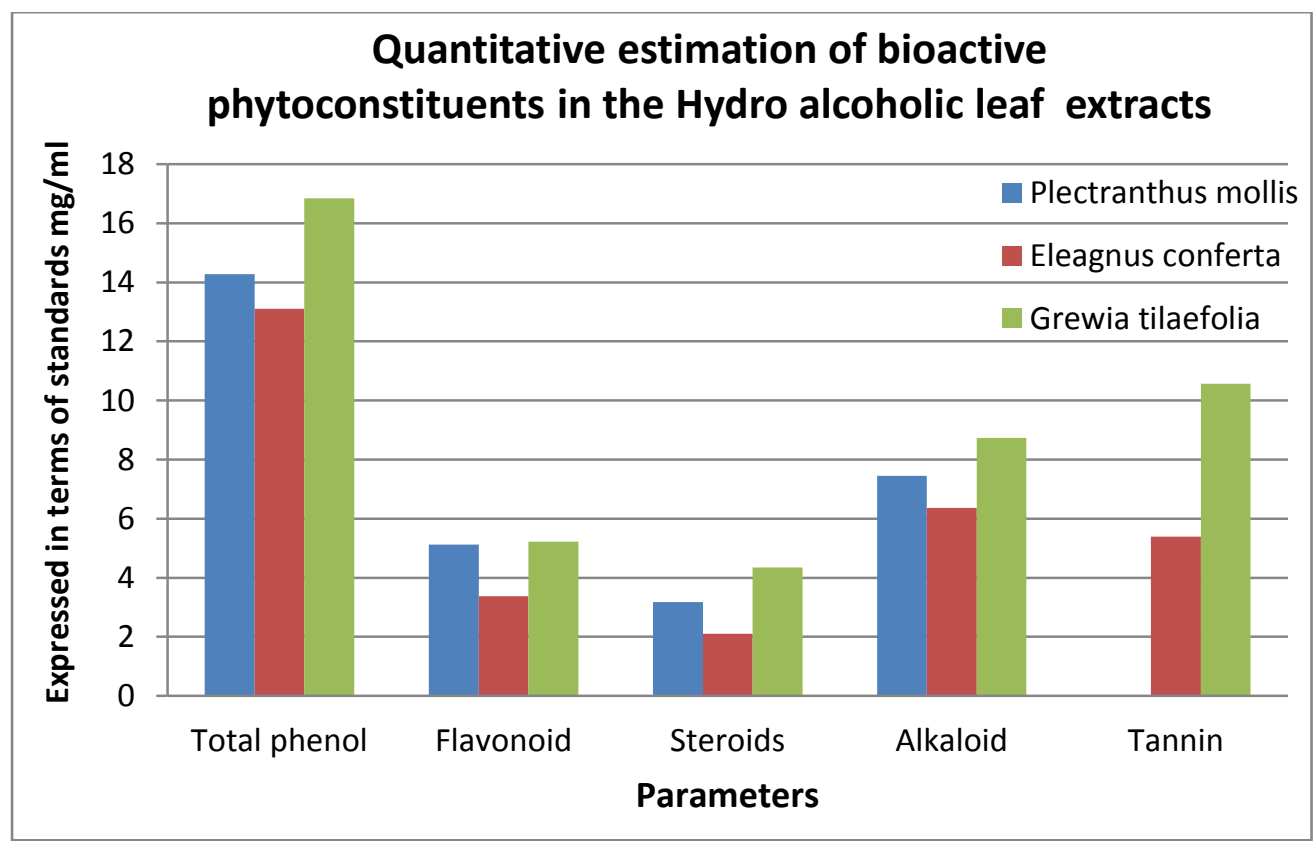

Image: 3 Graphical representation of Quantitative estimation of bioactive phytoconstituents in the Hydro alcoholic leaf extracts

\section{CONCLUSION}

Exposure to higher doses of arsenic can cause nausea and vomiting, decreased production of red and white blood cells, abnormal heart beat, harm to blood vessels, and a feeling of pinching by pins and needles in hands and feet. Symptoms of arsenic poisoning include headache, confusion, convulsion, diarrhoea, vomiting, and in severe cases it leads to coma and death. The present values showed the arsenic and cadmium was within the permissible limits and showed similarities with the previous findings. The observed concentrations of Chromium and Manganese in the chosen plant were found well under prescribed values.

The present study revealed that the focus of $\mathrm{Hg}, \mathrm{Cd}, \mathrm{Pb}, \mathrm{Cu}, \mathrm{Zn}, \mathrm{Ar}, \mathrm{Cr}, \mathrm{Mn}$ metals are within or remarkably much lower in limits recommended by WHO. The tested plants of Plectranthus mollis, Elaeagnus conferta and Grewia tilaefolia concentration showed minimum traces of mercury, Copper and Zinc were found good in concentrations, Presence of $\mathrm{Cu}$, and $\mathrm{Zn} \mathrm{might} \mathrm{be} \mathrm{a}$ useful supplement because these two elements are essential elements in trace concentrations for body metabolism. The other 
heavy metals like arsenic, cadmium, lead, mercury which are non necessary elements were found in low levels when compared to other findings.

Based on these results, all the metals are below the WHO permissible limits. Hence, the plant can be used for the development of drug and herbal products. Thus, on the basis of experimental outcome, it can be accomplished that the plant Grewia tilaefolia which has vast ethnomedicinal values estimated are safe and may not produce any harmful effect of metal toxicity during their remedial application and could also develop new drug entities from the plant.

Special concentration should be given to various form of metals distributed within the plant tissues, because metal forms in plants seems to have a decisive role in metal transfer to other organisms. Our examination revealed that heavy metals and trace elements present in the analyzed medicinal plants were within permissible limits of FAO \& WHO. Generally most of the herbal plants available in Nagaland, India are safe for human utilization as far as trace metal levels are concerned, as the level of pollution is almost nonexistent due to the absence of polluting industries. The analyzed therapeutic plants can be considered as potential sources for providing a sensible amount of the required elements in diet and establish it nutraceutical value for the traditional healers and herbal remedy users.

The plant based bio-active compounds have the effective response with minimal quantity, when compared to the synthetic compounds. The studies conducted on these three selected plants of Plectranthus mollis, Elaeagnus conferta and Grewia tilaefolia showed the presences of phytochemicals. The presence of phytochemicals (secondary metabolites) is responsible for their remedial effects. It further reflects a hope for the development of many more novel therapeutic agents or templates from such plants which in future may serve for the production of unnaturally improved therapeutic agents.

\section{REFERENCES}

[1]. Perumal samy R and Gopalakrishna kone, Current status of herbal and their future perspectives Nature proceedings; 2007.

[2]. Baker AJM Brooks RR, Terrestrial higher plants which hyperaccumulate metallic lements-A review of their distribution, ecology and phytochmistry. Biorecovery, $1989 ; 1: 81-126$

[3]. Meve U Species numbers and progress in asclepiad taxonomy Kew bulletin. 2002; 57: 459-464

[4]. Alam Muzaffer Sathavasan K Ali Usman S, Ramadas VNK and Chelladurai, Analytical Values of Sarcostemma acidum and Ceropegia juncea the Soma Plants in Ayurveda BMEBR. 1982; 3: $238-243$

[5]. Peter AGM \& De Smet, Herba remedies New Eng J Med. 2002; 347: 2046-2056

[6]. Bailey LH. The Standard Cyclopedia of Horticulture. New York: The MacMillian Company; 1950

[7]. Manvi M, Garg GP. Evaluation of Pharmacognostical parameters and Hepatoprotective activity in Bryonia alba Linn. J Chem Pharm Res. 2011;3:99_ 109.

[8]. Niamat R, Khan MA, Khan KY, Ahmad M, Ali B, Mazari P. et al. Element Content of Some Ethnomedicinal Ziziphus Linn. Species Using Atomic Absorption Spectroscopy Technique. J Appl Pharm Sci.2012;2:96-100.

[9]. Rodushkin I, Ruth T, Huhtasaari A. Comparison of two digestion methods for elemental determinations in plant material by ICP techniques. Anal Chim Acta. 1999;378:191-200.

[10]. Lapa AJ, Souccar C, Lima-Landman MTR, Castro MSA, Lima TCM. Métodos de avaliação da atividade farmacológica de plantas medicinais. Brazil: Sociedade Brasileira de Plantas Medicinais; 2003.

[11]. Rajurkar NS, Damame MM. Mineral content of medicinal plants used in the treatment of diseases resulting from urinary tract disorders. Appl Radiat Isot. 1998;49(7):773-6.

[12]. Zhang X, Ding W, Li J, Liu F, Zhou X, Tian S. Multi-elemental analysis of Ziziphora clinopodioides from different regions, periods and parts using atomic absorption spectrometry and chemometric approaches. Rev Bras de Farmacogn. 2015;25(5):465-72.

[13]. Wang HW, Liu YQ. Evaluation of trace and toxic element concentrations in Paris polyphylla from China with empirical and chemometric approaches. Food Chem. 2010;121(3):887-92.

[14]. Liu F, Liu WX, Ding WH, Lv GY, Zhou XY. Trace elements analysis by ICP-OES after microwave digestion of Medicago sativa L. seeds from differentlocations in Xinjiang. China Asian J Chem. 2014;26(12):3522-6.

[15]. Kierdorf U, Stoffels D, Kierdorf H. Element concentrations and element ratios in antler and pedicle bone of yearling red deer (cervus elaphus) stags-a quantitative x-ray fluorescence study. Biol Trace Elem Res. 2014;162(1-3):124-33.

[16]. Daiane D, do Nascimento PC, Jost CL, Denise B, de Carvalho LM, Andrea K. Voltammetric determination of lowmolecular- weight sulfur compounds in hydrothermal vent fluids - studies with hydrogen sulfide, methanethiol, ethanethiol and propanethiol. Electroanal. 2010;22(10):1066-71.

[17]. Njinga RL, Moyo MN, Abdulmaliq SY. Analysis of essential elements for plants growth using instrumental neutron activation analysis. Int J Agr. 2013:1-9.

[18]. Khan KY, Khan MA, Niamat R, Munir M, Fazal H, Mazari P. et al. Element content analysis of plants of genus Ficus using atomic absorption spectrometer. Afr J Pharm Pharmaco. 2011;5(3):317-21.

[19]. Belay K, Tadesse A, Kebede T. Validation of a method for determining heavy metals in some ethiopian spices by dry ashing using atomic absorption spectroscopy. Int J Innov Appl Stud. 2014;5(4):327-2.

[20]. Okigbo RN, Eme UE, Ogbogu S. Biodiversity and conservation of medicinal and aromatic plants in Africa. Biotechnol. Molocular Biology Review. 2008; 3(6): 127- 134.

[21]. UNESCO. Culture and Health, Orientation Texts - World Decade for Cultural Development 1988 - 1997, Document CLT/DEC/PRO, Paris, France, 1996: 129.

[22]. Lucy H, Edgar JD. Medicinal Plants: A reemerging Health aid. Electronic. Journal of Biotechnology. 1999; 2(2):1- 15.

[23]. Kala CP. Health traditions of Buddhist community and role of Amchis in trans- Himalayan region of India. Current Science. 2005; 89:1331-1338. 
[24]. UNESCO. FIT/504-RAF-48 Terminal Report: Promotion of Ethnobotany and the Sustainable Use of Plant Resources in Africa, Paris, France. 1998: 60.

[25]. Adesokan AA, Yakubu MT, Owoyele BV, Akanji MA. Effect of administration of aqueous and ethanolic extracts of Enantia chlorantha stem bark on brewer's yeast induced pyresis in rats. African Journal of Biochemistry Research. 2008; 2(7):165-169.

[26]. Nascimento GGF, Lacatelli J, Freitas PC, Silva GL. Antibacterial activity of plant extracts and phytochemicals on antibiotic-resistant bacteria. Brazil Journal Microbiology. 2000; 31(4):886-891.

[27]. National Academy of Sciences (NAS) Food and Nutrition Board, Commission on Life Sciences, National Research Council, Recommended Dietary Allowances. 10 th ed. Washington DC: National Academy Press; 1989.

[28]. Klevay IM. The role of copper, zinc, and other chemical elements in ischemic heart disease. In: Rennert OM, Chan WY, editors. Metabolism of Trace Elements in Man, Developmental Aspects. Boca Raton: CRC Press; 1984.

[29]. FAO/WHO. Evaluation of certain food additives and contaminants: fifty-seventh report of the Joint FAO/WHO Expert Committee on Food Additives. Geneva: World Health Organization, (WHO Technical Report Series, No. 909); 2002.

[30]. Gupta J, Gupta A, Gupta AK. Determination of trace metals in the stem bark of Moringa oleifera Lam. Int J Chem Stud. 2014;2(4):39-42.

[31]. Institute of Medicine. Dietary reference intakes for vitamin A, vitamin K, arsenic, boron, chromium, copper, iodine, iron, manganese, molybdenum, nickel, silicon, vanadium, and zinc. Washington DC: National Academy Press; 2001.

[32]. Hurley IS, Baley DI. The effects of zinc deficiency during pregnancy. In: Prasad AS, editor. Clinical, biochemical, and nutritional aspects of trace elements. Current topics in nutrition and disease. New York: Alan R. Liss, Manhattan Publisher;1982.

[33]. Dafalla A, Abdalla H. Determination the minerals contents of the roots of four medicinal plants as Asaudian indigenous plants using flame atomic absorption spectroscopy (FAAS) J Chem Pharm Res.2014;6(11):101-4.

[34]. Gupta J, Gupta A, Gupta AK. Determination of trace metals in the stem bark of Moringa oleifera Lam. Int J Chem Stud. 2014;2(4):39-42.

[35]. World Health Organization . Consultation on Tolerable Daily Intake from Food of PCDDs and PCDFs. Bilthoven: World Health Organization, Regional Office for Europe; 1991.

[36]. Ruan J, Wong MH. Aluminium absorption by intact roots of the Al-accumulating plant Camellia sinensis L. Agron. 2004;24(3):137-42.

[37]. Chaturvedi A, Bhawani G, Agarwal PK, Goel S, Singh A, Goel RK. Ulcer healing properties of ethanolic extract of eugenia jambolana seed in diabetic rats: Study on gastric mucosal defensive factors. Indian J Physiol Pharmacol. 2009;53(1):16-2

[38]. Ahmed MJ, Alam MS. A rapid spectrophotometric method for the determination of mercury in environmental, biological, soil and plant samples using diphenylthiocarbazone. J Spec. 2003;17(1):45-52.

[39]. Zhao D, Li HB, Xu JY, Luo J, Ma LQ. Arsenic extraction and speciation in plants: Method comparison and development. Sci Total Environ. 2015; 523:138-45.

[40]. Narayana B, Cherian T, Mathew M, Pasha C. Spectrophotometric determination of arsenic in environmentsal and biological samples. Indian J Chem Techn. 2006; 13(1):36-40.

[41]. 38. Pal A, Chowdhury UK, Mondal D, Das B, Nayak B, Ghosh A. et al. Arsenic burden from cooked rice in the populations of arsenic affected and non affected areas and kolkata city in west-bengal, india.Environ Sci Technol. 2009;43(9):3349-55.

[42]. WHO. Vanadium, in Air Quality Guidelines - Second Edition. WHO Regional Office for Europe; Copenhagen, Denmark: 2000.

[43]. WHO. Trace elements in human nutrition and health. A Report of a re-evaluation of the role of trace elements in human health and nutrition. 1996; $155-159$.

[44]. Raju GJN, Sarita P, Rao JCS, Rao KCB, Reddy SBCorrelation of trace elemental content in selected anticancer medicinal plants with their curative ability using particle induced X-ray emission (PIXE). J Med Plants Res. 2013;7:1081-1086.

[45]. Raju GJN, Sarita P, Rao JCS, Rao KCB, Reddy SBCorrelation of trace elemental content in selected anticancer medicinal plants with their curative ability using particle induced X-ray emission (PIXE). J Med Plants Res. 2013;7:1081-1086.

[46]. Vincent JBElucidating a biological role for chromium at a molecular level. Acc Chem Res. 2000;33:503-510.

\section{Author's Profile}

S.K.Gunavathy is currently working as Assistant Professor, Department of Chemistry, Srimad Andavan Arts and Science College (Autonomous), Tiruchirappalli, Tamil Nadu, India. She has completed M.Sc., Degree in Chemistry from NIT, Tiruchirappalli, Tamil Nadu, India.

Dr. H. Benita Sherine a is currently working as Assistant Professor, PG \& Research, Department Chemistry, Periyar E.V.R. College (Autonomous), Tiruchirappalli. She has awarded with a Ph.D. Degree in Chemistry from Bharathidasan University, Tiruchirappalli. The authors have published more than 25 research papers in reputed international journals. 